\title{
INTELECTUAIS E ROMANTISMO REVOLUCIONÁRIO
}

\author{
Marcelo Ridenti \\ Professor do Instituto de Filosofia e Ciências Humanas da Unicamp. Autor, entre outros livros, \\ de Em busca do povo brasileiro: artistas da revolução, do CPC à era da TV.
}

\begin{abstract}
Resumo: $\mathrm{O}$ artigo pondera sobre a trajetória de setores da intelectualidade brasileira dita de esquerda, a partir dos anos 60, marcados pelo romantismo revolucionário. Porém, com o avanço desigual e combinado do capitalismo, viriam a impor-se a atomização reificada da sociedade do espetáculo e o esvaziamento do ensaio geral de socialização da cultura. Esse processo tenderia a institucionalizar profissionalmente o meio intelectual e a afastá-lo do compromisso com as causas críticas da ordem.

Palavras-chave: cultura e política; intelectualidade brasileira; rebeldia e revolução.
\end{abstract}

$\mathrm{T}$ alvez não tenha havido um momento da história recente mais marcado pela convergência entre política, cultura, vida pública e privada que os anos 60 - não só na sociedade brasileira, sobretudo entre a intelectualidade. ${ }^{1}$ Para pensar essa convergência, usa-se aqui de um modo próprio o conceito de romantismo revolucionário, formulado por Michael Löwy e Robert Sayre (1995).

Eram anos de guerra fria entre os aliados dos Estados Unidos e os da União Soviética, mas surgiam esperanças de alternativas libertadoras no Terceiro Mundo, inclusive no Brasil, que vivia um processo acelerado de urbanização e modernização da sociedade. Naquele contexto, certos partidos e movimentos de esquerda, seus intelectuais e artistas, valorizavam a ação para mudar a História, para construir o homem novo, nos termos de Marx e Che Guevara. Mas o modelo para esse homem novo estava no passado, na idealização de um autêntico homem do povo, com raízes rurais, do interior, do "coração do Brasil", supostamente não contaminado pela modernidade urbana capitalista, o que permitiria uma alternativa de modernização que não implicasse a desumanização, o consumismo, o império do fetichismo da mercadoria e do dinheiro. São exemplos no âmbito das artes: o indígena exaltado no romance Quarup, de Antonio Callado (1967); a comunidade negra celebrada no filme Ganga Zumba, de Carlos Diegues (1963), e na peça Arena conta Zumbi, de Boal e
Guarnieri (1965); os camponeses no filme Deus e o Diabo na Terra do Sol, de Glauber Rocha (1963), etc. Em suma, buscava-se no passado uma cultura popular autêntica para construir uma nova nação, ao mesmo tempo moderna e dasalienada, no limite, socialista.

Eram versões de esquerda para as representações da mistura do branco, do negro e do índio na constituição da brasilidade, não mais no sentido de justificar a ordem social existente, mas de questioná-la. É a isso, em linhas gerais, que se pode chamar de romantismo revolucionário brasileiro do período, sem nenhuma conotação pejorativa. Recolocava-se o problema da identidade nacional e política do povo brasileiro, buscava-se a um tempo suas raizes e a ruptura com o subdesenvolvimento, numa espécie de desvio à esquerda do que se convencionou chamar ultimamente de Era Vargas, caracterizada pela aposta no desenvolvimento nacional, com base na intervenção do Estado.

Essa versão brasileira não se dissociava de traços do romantismo revolucionário da época em escala internacional: a liberação sexual, o desejo de renovação, a fusão entre vida pública e privada, a ânsia de viver o momento, a fruição da vida boêmia, a aposta na ação em detrimento da teoria, os padrões irregulares de trabalho e a relativa pobreza, típicas da juventude de esquerda na época, são características que marcaram os movimentos sociais nos anos 60 em todo o mundo, fazendo lembrar a velha tradição romântica. ${ }^{2}$ 


\section{OS ANOS ROMÂNTICOS}

O florescimento cultural e político internacional dos anos 60 ligava-se a uma série de condições materiais comuns a diversas sociedades, além das especificidades locais - no caso brasileiro, em especial, as lutas pelas reformas de base no pré-1964 e contra a ditadura após essa data, que levaram alguns ao extremo da luta armada. Essas condições comuns estavam presentes especialmente na Europa Ocidental e nos Estados Unidos, mas eram compartilhadas também por países em desenvolvimento, como o Brasil: crescente urbanização, consolidação de modos de vida e cultura das metrópoles, aumento quantitativo das classes médias, acesso crescente ao ensino superior, peso significativo dos jovens na composição etária da população, incapacidade do poder constituído para representar sociedades que se renovavam, avanço tecnológico (por vezes ao alcance das pessoas comuns, que passaram a ter cada vez mais acesso, por exemplo, a eletrodomésticos como aparelhos de televisão, além de outros bens, caso da pílula anticoncepcional - o que possibilitaria mudanças consideráveis de comportamento), etc. Essas condições materiais não explicam por si sós as ondas românticas de rebeldia e revolução, apenas possibilitaram que frutificassem ações políticas e culturais inovadoras e diversificadas, aproximando a política da cultura e da vida cotidiana, buscando colocar a imaginação no poder.

Foram características dos movimentos libertários dos anos 60, particularmente de 1968, no mundo todo: inserção numa conjuntura internacional de prosperidade econômica; crise no sistema escolar; ascensão da ética da revolta e da revolução; busca do alargamento dos sistemas de participação política, cada vez mais desacreditados; simpatia pelas propostas revolucionárias alternativas ao marxismo soviético; recusa de guerras coloniais ou imperialistas; negação da sociedade de consumo; aproximação entre arte e política; uso de recursos de desobediência civil; ânsia de libertação pessoal das estruturas do sistema (capitalista ou comunista); mudanças comportamentais; vinculação estreita entre as lutas sociais amplas e os interesses imediatos das pessoas; aparecimento de aspectos precursores do pacifismo, da ecologia, da antipsiquiatria, do feminismo, de movimentos de homossexuais, de minorias étnicas e outros que viriam a se desenvolver nos anos seguintes.

O ensaio geral de socialização da cultura ${ }^{3}$ brasileira dos anos 60 construiu-se sobre coordenadas históricas específicas, que podem ser observadas nas sociedades que adentram definitivamente na modernidade urbana capitalista, conforme sugestão de Perry Anderson: a "intersecção de uma ordem dominante semi-aristocrática, uma economia capitalista semi-industrializada e um movimento operário semi-insurgente". Ou seja, o modernismo caracteriza-se historicamente:

- pela resistência ao academicismo nas artes, indissociável de aspectos pré-capitalistas na cultura e na política, em que as classes aristocráticas e latifundiárias dariam o tom;

- pela emergência de novas invenções industriais de impacto na vida cotidiana, geradora de esperanças libertárias no avanço tecnológico;

- e pela proximidade imaginativa da revolução social, fosse ela mais "genuína e radicalmente capitalista" ou socialista (Anderson, 1986:18-19).

Já foi argumentado em outro trabalho (Ridenti, 1993:7681) que as coordenadas históricas do modernismo sugeridas por Anderson estavam presentes na sociedade brasileira, do final dos anos 50 até por volta de 1968: havia luta contra o poder remanescente das oligarquias rurais $\mathrm{e}$ suas manifestações políticas e culturais; um otimismo modernizador com o salto na industrialização a partir do governo Kubitschek; também um impulso revolucionário, alimentado por movimentos sociais e portador de ambigüidades nas propostas de revolução brasileira, democrático-burguesa (de libertação nacional), ou socialista, com diversas gradações intermediárias.

\section{Os Anos Pragmáticos}

Com a derrota das esquerdas brasileiras pela ditadura e os rumos dos eventos políticos internacionais, perdeuse a proximidade imaginativa da revolução social, paralelamente à modernização conservadora da sociedade brasileira e à constatação de que o acesso a novas tecnologias não correspondeu às esperanças libertárias no progresso técnico em si. Então, ficou explícito que o modernismo temporão não bebia na fonte da eterna juventude; e o ensaio geral de socialização da cultura frustrou-se antes da realização da esperada revolução brasileira, que se realizou pelas avessas, sob a bota dos militares, que depois promoveriam a transição lenta, gradual e segura para a democracia, garantindo a continuidade do poder político e econômico das classes dominantes.

Paradoxal é que a nova ordem da ditadura - uma vez devidamente punidos com prisões, mortes, torturas e exí- 
lio os que ousaram se insurgir abertamente contra ela soube dar lugar aos intelectuais e artistas de oposição. A partir dos anos 70 , concomitantemente à censura e à repressão política, ficou evidente o esforço modernizador que a ditadura já vinha esboçando, desde a década de 60 , nas áreas de comunicação e cultura, incentivando o desenvolvimento capitalista privado ou até atuando diretamente por intermédio do Estado.

As grandes redes de TV, em especial a Globo, surgiam com programação em âmbito nacional, estimuladas pela criação da Embratel, do Ministério das Comunicações e de outros investimentos governamentais em telecomunicações, que buscavam a integração e segurança do território brasileiro. Ganhavam vulto diversas instituições estatais de incremento à cultura, como a Embrafilme, o Instituto Nacional do Livro, o Serviço Nacional de Teatro, a Funarte e o Conselho Federal de Cultura. À sombra de apoios do Estado, floresceu também a iniciativa privada: criou-se uma indústria cultural, não só televisiva, mas também fonográfica, editorial (de livros, revistas, jornais, fascículos e outros produtos comercializáveis em bancas de jornal), de agências de publicidade, etc. Tornou-se comum, por exemplo, o emprego de artistas (cineastas, poetas, músicos, atores, artistas gráficos e plásticos) e intelectuais (sociólogos, psicólogos e outros cientistas sociais) nas agências de publicidade, que cresceram em ritmo alucinante a partir dos anos 70 , quando o governo também passou a ser um dos principais anunciantes na florescente indústria dos meios de comunicação de massa. ${ }^{4}$

Celso Frederico, seguindo trilhas abertas por Jameson, dá pistas significativas para compreender a inserção de setores artísticos e intelectuais de esquerda nesse processo. Para ele, com a terceira revolução tecnológica capitalista, a partir dos anos 60, "a esfera cultural e artística, totalmente envolvida pela mercantilização, deixou paulatinamente de ser um campo à parte dentro da vida social". Com a ocupação quase completa do espaço cultural pela lógica mercantil, tendia a diluir-se a presença da esquerda nessa área, na qual permanecera até então como "reduto, pólo de resistência contra os efeitos desumanizadores da lógica do capital" (Frederico, 1998:298-99).

A atuação cultural do regime civil-militar também implicou a modernização conservadora da educação, com a massificação (e degradação) do ensino público de primeiro e de segundo grau, o incentivo ao ensino privado e a criação de um sistema nacional de apoio à pós-graduação e à pesquisa para as universidades, nas quais a ditadura en- contrava alguns dos principais focos de resistência, que reprimiu duramente, mas sem deixar de oferecer uma alternativa de acomodação institucional. Buscava-se atender, dentro dos parâmetros da ordem estabelecida, às reivindicações de modernização que haviam levado os estudantes às ruas nos anos 60 .

$\mathrm{Na}$ esfera dos costumes, as forças da ordem também souberam adaptar para seus propósitos o que originariamente eram transgressões - e isso não ocorreu só na sociedade brasileira. Por exemplo, num artigo provocativo, "A consolação da revolução sexual", Jean-Claude Guillebaud observa que a liberação sexual teve um sentido de esquerda nos anos 60, ao "sacudir a velha moral, o velho mundo pudico, autoritário, patriarcal, arcaico", em que sua geração foi criada (1999:176). Contudo, essa liberação nos dias de hoje teria perdido seu caráter subversivo, ao contrário das auto-ilusões dos militantes de 1968, que, derrotados na política, teriam como consolo a suposta vitória da revolução sexual. Esta, de fato, teria sido digerida e reaproveitada pelo capitalismo, que soube transformá-la em mercadoria, num tempo marcado pelo que alguns especialistas chamam de desemprego estrutural, em que não se precisa mais canalizar para o trabalho todas as energias da população, a quem o mercado busca oferecer opções (inclusive sexuais) de diversão, para acomodá-la à ordem e lucrar. Hoje, segundo Guillebaud (1999:179) - invertendo as condições de 1968 -, "a virtude, a moral, a família são estruturas parasitas que se opõem à tirania do mercado".

$\mathrm{O}$ fato é que a sociedade brasileira foi ganhando nova feição e a intelectualidade que combatia a ditadura aos poucos adaptava-se à nova ordem, que criava até mesmo um nicho de mercado para produtos culturais críticos, censurando seletivamente alguns deles. Universidades, jornais, rádios, televisões, agências de publicidade, empresas públicas e privadas tendiam a fornecer ótimas oportunidades a profissionais qualificados, dentre os quais se destacavam os que se consideravam de esquerda, expoentes da cultura viva do momento imediatamente anterior.

A situação não se alterou muito após a redemocratização da sociedade brasileira, a partir de 1985, que daria sinal verde para uma parcela significativa dos intelectuais de oposição comprometer-se com a Nova Repúbli$c a$. Eram as "aves de arribação", a deixar o campo de uma oposição mais consistente à ordem estabelecida, na expressão de um artigo da época de Francisco de Oliveira (1985). 


\section{Nada será como antes. Nada?}

Ao menos desde o final da década de $70,{ }^{5}$ ia ficando cada vez mais evidente a necessidade de renovar os parâmetros da esquerda, em busca da revalorização da democracia, da individualidade, das liberdades civis, dos movimentos populares espontâneos, da cidadania, da resistência cotidiana à opressão, das lutas das minorias, entre outras.

Houve uma infinidade de manifestações nos diferentes campos da sociedade a expressar essa virada no pensamento e na prática de esquerda. Na esfera política, foi criado o Partido dos Trabalhadores (PT), ancorado num tripé: as Comunidades Eclesiais de Base da Igreja Católica, inspiradas na teologia da Libertação; o chamado novo sindicalismo, liderado pelos metalúrgicos do $\mathrm{ABC}$ paulista; além de intelectuais e remanescentes de organizações políticas marxistas-leninistas derrotadas pelo regime civil-militar. O PT procurava dar vez e voz aos deserdados, que haviam começado a se organizar em movimentos sociais a partir de meados dos anos 70. Paralelamente, surgia uma literatura para teorizar a importância e a autonomia desses movimentos em relação ao Estado e a outras instituições, inclusive os partidos. Por exemplo, num artigo muito difundido, Tilman Evers (1984) celebrava a independência dos movimentos e seu caráter libertário; apostava no PT como partido servo dos movimentos, jamais seu guia, como os tradicionais partidos de esquerda. Alguns anos depois, Eder Sader faria um balanço da experiência desses movimentos em Quando novos personagens entram em cena (1988). Por sua vez, vários intelectuais procuravam compreender os dilemas da esquerda, como os que participaram do debate, depois transformado em livro, As esquerdas e a democracia dentre eles, Carlos Nelson Coutinho, Francisco Weffort, Maria Victória Benevides, Marco Aurélio Garcia e Daniel Aarão Reis. (Garcia, 1986). ${ }^{6}$

Os acontecimentos dos anos 80 - da reformulação partidária brasileira de 1980, passando pelo fim da ditadura civil-militar em 1984, até a queda do Muro de Berlim em 1989, episódio emblemático da derrocada dos regimes prósoviéticos, que no Brasil culminaria com a auto-extinção do Partido Comunista Brasileiro, já na década de $90-$ consolidaram o esgotamento do modelo bolchevique de partido revolucionário no Brasil, embora uma ou outra organização continuasse posteriormente a se estruturar nesses moldes. Dentre outras razões, porque os militantes já não encontravam motivos para o auto-sacrifício em nome do Partido e da revolução. Se o sacrifício da individuali- dade parecera-lhes fazer sentido em conjunturas passadas, isso já não ocorreria no presente. Para a maioria, não teria mais cabimento integrar partidos que impusessem aos militantes o que Daniel Aarão Reis Filho chamou de "estratégia da tensão máxima". ${ }^{\text {? }}$

Ganhavam projeção, nos anos 80 , correntes de esquer$\mathrm{da}$ - quer se autodesignassem marxistas, quer não - que buscavam contato com a realidade imediata das vidas cotidianas, contra a visão doutrinária fechada de certas vertentes do marxismo.

Mas há o outro lado da moeda. Às vezes a (auto)crítica do engajamento dos anos 60 não foi senão a máscara para o triunfo da concepção (neo)liberal do indivíduo, da sociedade e da política. No lugar do intelectual indignado, dilacerado pelas contradições da sociedade capitalista, agravadas nas condições de subdesenvolvimento, passava a predominar o intelectual profissional competente e competitivo no mercado das idéias, centrado na carreira e no próprio bem-estar individual.

Entrava em franco declínio o modelo de intelectual ou artista de esquerda dos anos 60, engajado, altruísta, em busca da ligação com o povo - tido hoje por muitos como mera expressão do populismo, manipulador dos anseios populares; ou, na melhor das hipóteses, como arquétipo do intelectual quixotesco e ingênuo. Ia-se estabelecendo o protótipo do scholar contemporâneo, egocêntrico, desvinculado de compromissos sociais, a não ser que eles significassem avanço em suas carreiras profissionais individuais, como as dos inúmeros professores que já foram críticos da ordem capitalista a ocupar cargos públicos em governos que adotam medidas neoliberais. Atuam como técnicos a serviço do funcionamento saudável da ordem estabelecida, sem maiores dramas de consciência, talvez se agarrando ainda à ideologia de que estão no poder para o bem do povo e da nação, uma vez amadurecidos e livres das utopias voluntaristas dos anos 60 , que só aparentemente teriam sido revolucionárias.

Os tempos mudaram e, especialmente a partir dos anos 80 , já era visível o progressivo trajeto de desaparecimento do intelectual ou artista atormentado com sua condição relativamente privilegiada numa sociedade subdesenvolvida e desigual, como a brasileira. Gradativamente, a ânsia de muitos intelectuais de esquerda ia deixando de dirigir-se para a ruptura coletiva da condição do subdesenvolvimento nacional e da exploração de classe; a busca passaria a ser o acesso individual ao desenvolvimento de um mundo globalizado, ainda que muitas vezes o discurso continuasse com tons esquerdistas. 
Aos poucos, foi-se esgotando o arquétipo do intelectual ou artista rebelde, cada vez mais raro nos dias de hoje. Os intelectuais críticos e comprometidos com a superação das contradições da modernidade capitalista tendem a dar lugar a intelectuais resignados, contemplativos das eternas contradições, contra as quais pouco ou nada poderiam fazer. O intelectual militante, libertário, é substituído pelo intelectual passivo, a fruir sem culpa sua liberdade e relativa autonomia na modernidade em eterna mutação. Em vez de colocar-se em sintonia com "os sinais da rua", como por exemplo sugere Berman (1986 e 1987), esse intelectual-narcisista apenas observa o movimento perpétuo da rua, instalado na janela à prova de balas de seu confortável gabinete, com vista para o mar, que não cansa de mirar, aguardando notícias da última moda intelectual no exterior, ou a oportunidade de conferi-la pessoalmente em Paris, Londres ou Nova York.

$\mathrm{O}$ acerto de contas com os anos 60 colocava a intelectualidade brasileira dos anos 80 na fronteira entre uma (auto)crítica que poderia redundar na continuidade do engajamento contra a ordem estabelecida, agora num patamar superior - o intelectual ao mesmo tempo dilacerado pelas contradições da modernidade e engajado prazerosamente no processo de transformação, sem renunciar à sua individualidade -, ou uma (auto)crítica que envolveria o desaparecimento do intelectual inconformista, tendência que ganharia cada vez mais força nos anos seguintes. As personalidades modernas, ao "assumir a fluidez e a forma aberta dessa sociedade" (Berman, 1986:94), podem implicar o reconhecimento de que pouco caberia fazer para mudar as encruzilhadas históricas, para resolver as contradições da modernidade, que teria um movimento próprio de eterna autodestruição criadora, a que todos deveriam se ajustar.

A vivência das contradições da modernidade pode levar o intelectual ao engajamento na mudança, ou a preferir adaptar-se à ordem em transformação constante, aceitando o "destino", livre do dilaceramento existencial. Em vez de intelectual revoltado contra o mundo, ou revolucionário a propor um novo mundo - típico dos anos 60 -, consolida-se o intelectual reconciliado com o mundo, no qual reconheceria o eterno e inevitável movimento em que deve se inserir, e não combater, usufruindo ao máximo o prazer e a dor de viver em meio às intempéries da modernidade.

De modo que se estabeleciam tardiamente - durante o período da ditadura, consolidando-se posteriormente com a redemocratização no Brasil - novas condições que fa- zem lembrar os comentários de Jacoby (1990) sobre o declínio do intelectual atuante na vida pública da sociedade norte-americana já na década de 50: os intelectuais e artistas estariam ocupados e preocupados especialmente com as exigências das carreiras profissionais, como na Universidade; à medida que a vida profissional prospera, a cultura pública fica mais pobre e mais velha; haveria a substituição crescente de empresários, trabalhadores e profissionais independentes por empresas corporativas, processo indissociável da explosão da educação superior; desaparecimento do espaço urbano barato e agradável que podia nutrir uma intelligentsia boêmia, modelar de uma geração de intelectuais (diferente da boêmia massificada de hoje, comercializada e popularizada); eliminação das moradias baratas, restaurantes, cafés e livrarias modestos; comercialização acelerada da cultura, num cenário em que "a literatura e a crítica se tornam carreiras, não vocações", com autores independentes dando lugar à profissionalização da vida cultural.

A institucionalização de intelectuais e artistas neutralizaria a liberdade de que em teoria dispõem, de modo que eventualmente o sonho com a revolução conviveria com o investimento na profissão, na qual prevaleceria a realidade cotidiana da burocratização e do emprego. A profissionalização da vida intelectual nos limites do campus universitário conduziria à privatização ou à despolitização, à transferência da energia intelectual de um domínio mais amplo para uma disciplina mais restrita, em que as pressões da carreira e da publicação intensificariam a fragmentação do conhecimento. Esse processo ocorreria lentamente: "a transformação do ambiente do intelectual tradicional não é instantânea; ela é paralela ao declínio das cidades, ao crescimento dos subúrbios e à expansão das universidades" (Jacoby, 1990:245). Tudo isso misturado a uma recomposição do público, ao sucesso da televisão, à expansão dos subúrbios, deterioração das cidades e inchaço das universidades.

Não seria o caso de retomar aqui todo o pensamento de Jacoby para ajudar a explicar em outro contexto o declínio público da intelectualidade brasileira de esquerda. Mas pode-se imaginar um exemplo de como se esgarçou o espaço para a produção de uma intelectualidade radical: a São Paulo dos anos 60 contrastada com a de hoje. Naqueles anos, o ponto nevrálgico de encontro de artistas e intelectuais estava num breve espaço geográfico no centro da cidade, em que se concentravam o Teatro de Arena, o Cine Bijou, a Faculdade de Filosofia e outras da Universidade de São Paulo (USP), escritórios de arquite- 
tos, advogados e outros profissionais liberais engajados, todos se encontrando em restaurantes e bares da região, como o Redondo, na confluência entre a avenida Ipiranga e as ruas da Consolação e Teodoro Baima. Ali circulavam: o pessoal de teatro dos inovadores Arena e Oficina, escritores, cineastas, artistas plásticos, jovens representantes da insurgente música popular brasileira, professores da USP, militantes do movimento estudantil e de organizações de esquerda, enfim, todo um conjunto que representaria o florescimento cultural do período.

Hoje alunos e professores estão instalados no distante campus universitário da USP no Butantã, e muitos deles se espalharam pelas inúmeras universidades públicas e privadas que surgiram pelo interior do Estado e por outras unidades da federação ao longo dos anos, onde encontraram seu lugar profissional. O pessoal do teatro em geral alcançou êxito na televisão ou na indústria dos espetáculos teatrais. Os cineastas encontraram apoio na Embrafilme e outras alternativas de financiamento público que a sucederam, quando não nas agências de publicidade. Artistas plásticos viram frutificar um mercado rentável para suas obras, escritores se deram bem em jornais ou na expansão da mídia em geral, sem contar a crescentemente próspera indústria do livro. Vários músicos da MPB alcançariam sucesso de mercado maior que artistas de qualquer outro setor. E os políticos radicais de então encontrariam lugar nos mais diversos partidos da ordem, do PMDB ao PSDB, passando até pelo PT - cada vez mais confiável - e outros partidos, pelos quais muitas vezes chegaram a governos municipais, estaduais e federais. Inviabilizava-se a condensação de uma intelligentsia crítica num espaço geográfico e histórico criativo. Talvez uma das imagens mais expressivas da mudança e do esvaziamento desse espaço esteja no destino do local do famoso bar Redondo: virou uma loja de fast food.

Assim, pode-se constatar, com certo desencanto, os rumos que tomou uma parcela da intelectualidade que já se propôs a mudar o mundo e a vida, cuja despolitização quando não mudanças de rota em direção à direita - talvez não se deva apenas e essencialmente à vontade dos agentes, mas às próprias transformações por que passou a sociedade brasileira.

Que ninguém se iluda: não há como voltar às circunstâncias do passado de oportunidades perdidas de um ponto de vista de esquerda. É sabido que a tendência à fragmentação social do capitalismo de hoje dificulta projetos coletivos alternativos, como aqueles dos anos 60 , levando muitas vezes os atuais artistas e intelectuais engajados a meramente transferir a uma dada causa seus apoios e prestígios pessoais, por exemplo, declarando apoio a certos candidatos ou partidos no horário político obrigatório na televisão. Mas nem por isso seria adequado conformarse com o presente de burocratização inofensiva das atividades intelectuais e artísticas.

Para um estudo do enfraquecimento da arte política nos anos 70 e sobretudo nos 80 e 90, é instigante a análise de Jameson (1994) sobre os problemas envolvidos na produção de uma arte política em nossos dias, em que o capitalismo quase inviabilizaria quaisquer atividades grupais que pudessem embasar socialmente uma arte subversiva, numa era de ocupação quase completa do espaço cultural pela lógica mercantil. Haveria uma atomização reificada, imposta pelo capitalismo de hoje. Jameson admite, contudo, como fundamento social para uma nova arte política e uma produção cultural autêntica a ser criada, a constituição de um grupo novo e orgânico, por meio do qual o coletivo abriria caminho na atomização reificada da vida social capitalista, a partir da luta de classes.

Parece que seria equivocado reproduzir ao pé da letra propostas culturais e políticas dos anos 60. Mas seria possível encontrar alternativas melhores de inserção da sociedade brasileira e de sua cultura no mundo de hoje do que o ceticismo passivo, de submissão à nova ordem mundial do “consenso de Washington”. Não cabe reviver o passado, mas isso não implica a inviabilidade de retomar suas esperanças, apostar em novos projetos coletivos de transformação social - inclusive nas esferas intelectuais e artísticas - em vez da carreira individual de cada um no mercado.

Nesses anos todos, a sociedade brasileira continuou submetida à "subordinação interiorizada e imperceptível" de um "complexo de experiências, relações e atividades" que constituem a hegemonia burguesa, para usar uma formulação de Chauí (1987:21-2). Ela está ancorada no conceito de hegemonia de Raymond Williams, derivado de Gramsci, que envolve "um conjunto de práticas e expectativas sobre a totalidade da vida: nossos sentidos e distribuição de energia, nossa percepção de nós mesmos e nosso mundo. É um sistema vivido de significados e valores - constitutivo e constituidor - que, ao serem experimentados como práticas, parecem confirmar-se reciprocamente. Constitui assim um senso da realidade para a maioria das pessoas na sociedade, um senso de realidade absoluta, porque experimentada, e além da qual é muito difícil para a maioria dos membros da sociedade movimentar-se, na maioria das áreas de sua vida." (Williams, 1979:113). 
Não há dúvida de que hoje predomina o senso de realidade experimentada que supõe a reprodução eterna da sociabilidade capitalista. Mas por que não inventar uma contra-hegemonia para os novos tempos, alternativa à hegemonia neoliberal e à atomização reificada da sociedade do espetáculo, nos termos respectivamente de Jameson (1994) e Debord (1967)? Utopia irrealizável? Talvez não. O recente Fórum Social de Porto Alegre, o movimento "Arte contra a barbárie" - que desde 1999 tem mobilizado artistas e intelectuais comprometidos com a "função social da arte" no Brasil - e outros indícios sinalizam que a roda-viva da História não parou na posição mais confortável para os donos do poder.

\section{NOTAS}

E-mail do autor: ridenti@dualtec.com.br

Neste artigo, o autor retoma e sintetiza idéias expostas mais longa e sistematicamente em alguns de seus últimos escritos sobre cultura e política a partir dos anos 60. É o caso do livro Em busca do povo brasileiro: artistas da revolução, do CPC à era da TV (Ridenti, 2000a), e dos artigos "O sucesso no Brasil da leitura do Manifesto Comunista feita por Marshall Berman" (Ridenti, 1998), e "Intelectuais, artistas e estudantes: Paris, 1968" (Ridenti, 2000b).

1. Intelectualidade entendida como "categoria social definida por seu papel ideológico: eles são os produtores diretos da esfera ideológica, os criadores de produtos ideológico-culturais", o que engloba "escritores, artistas, poetas, filósofos, sábios, pesquisadores, publicistas, teólogos, certos tipos de jornalistas, certos tipos de professores e estudantes etc.”, como define Michael Löwy (1979:1).

2. Veja-se, por exemplo, o que diz Jerrold Seigel a respeito do perfil dos boêmios de Paris do século XIX (Seigel, 1992).

3. O termo é de Walnice Nogueira Galvão (1994).

4. Um balanço expressivo da criação e do avanço da indústria cultural nos anos de ditadura, inclusive com dados estatísticos e rica menção de fontes empíricas e bibliográficas, encontra-se em A moderna tradição brasileira, de Renato Ortiz (1988).

5. Em 1979 entrou em vigor a lei da anistia aos condenados políticos pela ditadura; em 1980 ressurgiria o pluripartidarismo, entre outras medidas que mudavam a cena política brasileira.

6. Os livros mencionados são uma amostragem relativamente aleatória de um movimento intelectual e político muito mais amplo. Eles são citados por indicar reflexões de intelectuais engajados, como sintoma da procura de novos caminhos por parte das esquerdas, valorizando os "sinais das ruas" e a democracia.

7. Essa estratégia envolveria uma série de mecanismos: o complexo da dívida do militante com a organização comunista, o leque das virtudes do revolucionário modelo, o massacre das tarefas com que o Partido sobrecarregaria seus integrantes, a celebração da autoridade dos dirigentes, a ambivalência das orientações partidárias, bem como a síndrome da traição - pela qual seriam renegados aqueles que deixassem o Partido. (Reis Filho, 1991).

\section{REFERÊNCIAS BIBLIOGRÁFICAS}

ANDERSON, P. "Modernidade e revolução". Novos Estudos Cebrap. São Paulo, v.14, fev. 1986, p.2-15.

BERMAN, M. Tudo que é sólido desmancha no ar. São Paulo, Cia das Letras, 1986.

"Os sinais da rua: uma resposta a Perry Anderson". Presença. Rio de Janeiro, n.9, fev. 1987, p.122-38.

CHAUÍ, M. Conformismo e resistência. $2^{\text {a }}$ ed. São Paulo, Brasiliense, 1987.

DEBORD, G. La société du spetacle. Paris, Buchet-Chastel, 1967.

EVERS, T. "Identidade, a face oculta dos movimentos sociais". Novos Estudos Cebrap. São Paulo, v.2, n.4, abr. 1984, p.11-23.

FREDERICO, C. "A política cultural dos comunistas". In: QUARTIM DE MORAES, J. (org.). História do marxismo no Brasil, III. Teorias. Interpretações. Campinas, Ed. da Unicamp, 1998, p.275-304.

GALVÃO, W.N. "As falas, os silêncios”. In: SOSNOWSKI, S. e SCHWARZ, J. (orgs.). Brasil: o trânsito da memória. São Paulo, Edusp, 1994.

GARCIA, M.A. (org.). As esquerdas e a democracia. Rio de Janeiro, Paz e Ter$\mathrm{ra} / \mathrm{Cedec}, 1986$

GUILLEBAUD, J.-C. “A consolação da revolução sexual”. In: GARCIA, M.A. e VIEIRA, M.A. Rebeldes e contestadores - 1968: Brasil, França, Alemanha. São Paulo, Ed. Fundação Perseu Abramo, 1999, p.173-79.

JACOBY, R. Os últimos intelectuais. São Paulo, Edusp/Trajetória Cultural, 1990.

JAMESON, F. "Reificação e utopia na cultura de massa". Crítica Marxista. São Paulo, Brasiliense, v.1, n.1, 1994, p.1-25.

LÖWY, M. Para uma sociologia dos intelectuais revolucionários. São Paulo, Ciências Humanas, 1979.

LÖWY, M. e SAYRE, R. Revolta e melancolia - o romantismo na contramão da modernidade. Petrópolis, Vozes, 1995.

OLIVEIRA, F. de. "Aves de arribação: a migração dos intelectuais". Lua Nova. São Paulo, Cedec, v.2, n.3, out.-dez.1985.

ORTIZ, R. A moderna tradição brasileira - cultura brasileira e indústria cultural. São Paulo, Brasiliense, 1988.

REIS FILHO, D.A. A revolução faltou ao encontro. São Paulo, Brasiliense, 1991.

RIDENTI, M. O fantasma da revolução brasileira. São Paulo, Ed. Unesp, 1993.

"O sucesso no Brasil da leitura do Manifesto Comunista feita por Marshall Berman”. In: REIS FILHO, D.A. (org.). O Manifesto Comunista 150 anos depois. Rio de Janeiro/ São Paulo, Contraponto/ Fund. Perseu Abramo, 1998, p.187-207.

Em busca do povo brasileiro: artistas da revolução, do CPC à era da TV. Rio de Janeiro, Record, 2000a.

"Intelectuais, artistas e estudantes: Paris, 1968". In: REIS FILHO, D.A. (org.). Intelectuais, história e politica (séculos XIX e XX). Rio de Janeiro, 7 Letras, 2000b, p.247-70.

SADER, E. Quando novos personagens entram em cena. Rio de Janeiro, Paz e Terra, 1988.

SEIGEL, J. Paris boêmia - Cultura e politica, os limites da vida burguesa, 18301930. Porto Alegre, L\&PM, 1992.

WILLIAMS, R. Marxismo e literatura. Rio de Janeiro, Zahar, 1979. 